\title{
Self Nano-emulsifying Drug Delivery System to Enhance Solubility and Dissolution of Candesartan Cilexetil
}

\author{
Pathuri Raghuveer*, Avula Prameela Rani \\ University College of Pharmaceutical Sciences, Acharya Nagarjuna University, Guntur, Andhra Pradesh, INDIA.
}

\begin{abstract}
Aim: Self nano-emulsifying drug delivery system (SNEDDS) of candesartan cilexetil was explored to enhance its oral bioavailability. SNEDDS has tremendous potential in enhancing oral bioavailability of poorly aqueous soluble therapeutic agents. SNEDDS are pre-concentrate mixture of oil, surfactant and co-surfactant produces nanoemulsion after oral administration due to mild agitation produced by gastro motility within the size range of 20-200nm. Methodology: The formulations were developed by selecting capmul $\mathrm{MCM}^{\circledast}$, triacetin $^{\circledast}$ and caprylic acid ${ }^{\circledR}$ under the oil phase based on solubility of drug; cremophore $\mathrm{RH}_{4} 40^{\circledR}$, brij $35^{\circledR}$ under surfactants category and transcutol P under co-surfactant on basis of their emulsification property. Optimum concentrations were choosen from the Terinary phase diagrams and evaluated for their properties. Results: From the results of ternary diagrams 16 formulations were selected (A1, $A 2$, $\mathrm{A} 3, \mathrm{~A} 4, \mathrm{~B} 1, \mathrm{~B} 2, \mathrm{C} 1, \mathrm{C} 2, \mathrm{C} 3, \mathrm{C} 4, \mathrm{D} 1, \mathrm{D} 2, \mathrm{E} 1, \mathrm{E} 2, \mathrm{~F} 1, \mathrm{~F} 2)$ and subjected to characterization studies. Best formulations were subjected to particle size analysis and in vitro release studies. Among selected formulations, $\mathrm{A} 1$ and $\mathrm{C} 1$ have shown high in vitro drug release profiles with less selfemulsification time having grade A dispersibility without any precipitation and phase separation. Discussion: Concentration of surfactant helps
\end{abstract}

in reducing the size of the particle when compared to the co-surfactant concentration. Enhanced dissolution of candesartan cilexitil may be attributed to the spontaneous formation of nanoemulsion in vitro with a decreased particle size that leads to the increased surface area leaving the drug candesartan as finely dispersed particles in dissolution media. Conclusion: Formulation $\mathrm{C} 1$ consists of triacetin oil $30 \% \mathrm{w} / \mathrm{w}$, cremophore $\mathrm{RH} 406 \% \mathrm{w} / \mathrm{w}$ and transcutol P 64\%w/w showed best emulsification characteristics like $99 \%$ percent transmittance, with increased dissolution profile (98\%) than pure drug (45\%) with nano range goblet size $(165.9 \mathrm{~nm})$. Key words: Candesartan cilexetil, Cremophor RH 40, Transcutol P, Self Nano-emulsifying Drug Delivery Systems, Dissolution Enhancement.

\section{Correspondence}

\section{Mr. Pathuri Raghuveer}

Assistant Professor, University College of Pharmaceutical Sciences, Acharaya Nagarjuna University, Guntur-522510, Andhra Pradesh, INDIA.

Phone no: +91-9177230111

Email: prvpharma88@gmail.com

DOI: $10.5330 /$ ijpi.2020.4.88

\section{INTRODUCTION}

Advances of combinational chemistry and high throughput screening leads to identification of many therapeutic agents with greater potency, but most of them fail to obtain their maximum therapeutic importance due to their poor aqueous solubility, ${ }^{1}$ which might be a major obstacle while designing oral drug delivery system. If formulated with lipids oral bioavailability of poor aqueous soluble drugs may be improved, ${ }^{2}$ which leads to increased attention towards lipid-based formulations, among them Self Nano-emulsifying Drug Delivery Systems (SNEDDS) have emerged as one of the most effective dosage form for their proven ability to thermodynamic stability and enhanced bioavailability. ${ }^{3}$

SNEDDS were defined as isotropic mixtures of the drug, oil, surfactant and co-surfactant, form nanoemulsions when administered orally by mild agitation in the gastric tract with droplet sizes between 20 and $200 \mathrm{~nm} .{ }^{4,5}$ SNEDDS has more superiority than other lipid-based drug delivery systems i.e. by producing nano-size particles which has a high interfacial area that enhances the dissolution and increases penetration of drug due to the presence of lipid and emulsifiers. ${ }^{6}$ SNEDDS produces more reproducible plasma concentrations of drugs by reducing hepatic clearance by blocking cytochrome $\mathrm{P} 450$ and drug absorption through lymphatic system due to the presence of lipid in the formulation. ${ }^{7,8}$

Candesartan cilexetil (CDN) belongs to Angiotensin Receptor Blockers (ARBs) and classified as class-II into the Biopharmaceutical Classification System (BCS), which is low soluble $(0.00204 \mathrm{mg} / \mathrm{mL})$ and high permeable drugs (Log P - 7.53). Candesartan acts by competing with angiotensin II for binding at AT1 receptor subtype. As angiotensin II is a vasoconstrictor and also stimulates the synthesis and release of aldosterone, blockage of its effects results in a decrease in systemic vascular construction. ${ }^{9} \mathrm{CDN}$ has low bioavailability around $40 \%$ due to its low solubility.

CDN available in flexible doses as a tablet $(4,8,16,32 \mathrm{mg})$, possessing solubility related dissolution problems as their Dose-Solubility ratio was very high (64), showing the necessity for a dosage form having the ability to enhance dissolution there by bioavailability issues with scalable and cost-viable techniques. Bioavailability enhancing methods like polymeric micelles, ${ }^{10}$ cyclodextrin inclusions, ${ }^{11}$ solid dispersion ${ }^{12}$ and surface stabilized nanoparticles, ${ }^{13}$ etc., may be well served for bioavailability enhancement. However these systems have certain advantages related to solubility enhancement, use of the large amount of complexing agent, high concentration of co-solvents used for solubilization causes toxicity and high energy procedural and scale-up constraints. The present simple technique is aimed to develop SNEDDS of CDN for achieving enhanced bioavailability by increasing solubility and dissolution profile with high reproducibility and scalable method. ${ }^{14}$ Various oils, surfactants were screened for suitability, capmul MCM (glyceryl caprylate), triacetin and caprylic acid was selected as oil phase and cremophor RH40 and trancutol P were selected for formulation optimization. 


\section{MATERIALS AND METHODS}

\section{Materials}

Candesartan cilexetil was obtained as a gift sample from Aurbindo Pharma, Visakhapatnam and Andhra Pradesh. Brij 35, Triacetin, Caprylic acid, Span 20, Span 80, Tween 20, Tween 80, PEG 200 and Triton X-100 were procured from Loba chem. Pvt. Ltd., Mumbai, India. Cremophor RH40 was a gift sample provided by B.A.S.F Corporation. Transcutol P was a gift sample provided by Avra Synthesis Pvt Ltd, Hyderabad, India. Capmul MCM is gifted by Abitec Corporation, USA. Kalonji oil and Apricot kernel oil was purchased from Holy Naturals Pvt. Ltd, Chia seed oil purchased from Urban Platter Company. Coconut oil was purchased from Aromatique. Corn oil, Arachis oil and olive oil were purchased from Deve herbs, Delhi. Neem oil was purchased from Shree biotech and research inputs, MP. All the components used for the study are in pharmaceutical grade.

\section{Solubility studies}

It is an important parameter for the selection of excipients for SNEDDS. To determine the solubility excess amount of the drug (candesartan cilexetil) was dissolved in the $2 \mathrm{ml}$ of oil, surfactant and co-surfactant. ${ }^{15}$ These mixtures were kept in a cyclo mixture for $72 \mathrm{hrs}$ to facilitate solubility. Then these samples were centrifuged at $3000 \mathrm{rpm}$ for $30 \mathrm{~min} .{ }^{16}$ The supernatant liquid was collected, filtered and seen for the absorbance values using UV-VIS Spectrophotometer at $254 \mathrm{~nm}$.

\section{Construction of Ternary Phase Diagram}

To identify the self nano-emulsifying region and to optimize percentage of oil, surfactant and co-surfactant terinary phase diagrams were constructed in the absence of candesartan. The various mixture of S-mix was prepared by using surfactant and co-surfactant from 1:1 to 1:9; 2:1 to 9:1 as shown in Table 1 . All S-mix ratios were examined manually for clear nanoemulsion formation upon dilution with water. The ratios which formed nanoemulsion are subjected to the ternary diagram for analyzing the nano region followed by \% transmittance. By using particle size analyzer, we can determine particle size. ${ }^{17}$

\section{Formulation of liquid SNEDDS}

SNEDDS formulations were prepared by using components like oil, surfactant and co-surfactant mixing in different ratios. ${ }^{18} \mathrm{~A}$ unit dose of candesartan cilexetil (4mg) was loaded into the oil. The SNEDDS were prepared by dissolving the drug in oil and by adding surfactant and co-surfactant. ${ }^{19}$ The resultant mixture was mixed continuously by using a vertex mixture to get a homogenous isotropic mixture to add drop by drop water to form an emulsion..$^{20}$ This is also known as the self-emulsification method (also known as Phase inversion composition method; standard admixture method). ${ }^{21}$

\section{CHARACTERIZATION}

Centrifugation study: Screened formulations were subjected to centrifugation at $5000 \mathrm{RPM}$ for $30 \mathrm{~min}$. The formulation was subjected to visual observation for any precipitation, phase separation and cracking. Stable formulations are selected for further works. ${ }^{22}$

Self-emulsification Time: SNEDDS were subjected to Self-emulsification time using standard USP dissolution apparatus type II. optimized formulation One $\mathrm{ml}$ was added to $500 \mathrm{ml}$ of double distilled water in apparatus maintaining at $35 \pm 0.5^{\circ} \mathrm{C}$ and $50 \mathrm{RPM}$ to provide gentle agitation by paddle. The in vitro performance of optimized formulations was observed visually. ${ }^{23}$

\% Transmittance: Candesartan loaded SNEDDS was reconstituted with distilled water and visually observed for turbidity. Therefore, its \% transmittance was measured with the help of a UV spectrophotometer using water as blank at $638.2 \mathrm{~nm} .{ }^{24}$

Visual assessment of emulsification ability: The undiluted formulations were taken into a volumetric flask and add $20 \mathrm{~mL}$ of distill water and make inversions. The number of volumetric inversions necessary to form an emulsion indicates the ease of formation of the emulsion. The formed emulsion was visually observed for its clarity and turbidity. ${ }^{25}$

Particle Size analysis: The average droplet size and poly dispersibility index (PDI) of optimized formulations were determined using photon correlation spectroscopy (PCS). Measurements were made in triplicate using Zetaseizer 1000 HS (Malvern Instruments), wherein light scattering was monitored at $25^{\circ} \mathrm{C}$ at a $90^{\circ}$ angle..$^{24}$

Dispersibility Test: All formulations were assessed for spontaneous formation for emulsification. SNEDDS were diluted with distilled water in the ratio $1: 200(\mathrm{v} / \mathrm{v})$ stirred by manually at room temperature. The type of dispersion was graded from grade A to E. ${ }^{26}$

In vitro drug release study: The in vitro drug release study is performed for formulations by filling them in suitable capsule size, using the USP type II dissolution test apparatus in $900 \mathrm{ml}$ of $0.05 \mathrm{M}$ Phosphate buffer and $\mathrm{pH} 6.5$ as the medium at $37 \pm 0.5^{\circ} \mathrm{C}$ with $50 \mathrm{RPM}$. The in vitro drug release was conducted for $60 \mathrm{~min}$. $5 \mathrm{ml}$ samples were withdrawn from the basket at 5.10.15.30, 45, $60 \mathrm{~min}$. After the removal of the sample, the same amount of fresh medium was added. Samples were subjected to check absorbance by using UV-spectrophotometer at $254 \mathrm{~nm}$. Percent drug release and cumulative drug release were calculated from the standard curve. ${ }^{27}$

\section{RESULTS}

\section{Solubility study}

Solubility studies were conducted to identify suitable SNEDDS components possessing maximum drug solubility which is an imperative for achieving maximum drug loading. Appropriate selection of constituents will also ensure better emulsification efficiency. The solubility of the drug was conducted in different oils LCT's (Apricot kernel oil, kalonji oil, chia seed oil, coconut oil, Arachis oil, olive oil, Corn oil, Neem oil) and MCT's which has $\log \mathrm{P} \geq 4.5$ (Capmul MCM, Triacetin, Caprylic acid) also favors transportation through intestinal lymphatic's. ${ }^{28}$ The correct blend of surfactant of low and high HLB values leads to the formation of nanoemulsions. ${ }^{14}$ Solubility studies were conducted in surfactants and co-surfactants having high and low HLB values Cremophor RH 40(14 to 16); Brij 35 (16); Tween 80 (15); Span 80(4.3); Triton X-100(13.5); Transcutol P(4), PEG 200 (11); Tween 20

Table 1: Construction of Ternary phase diagrams for different ratios.

\begin{tabular}{ccccc} 
S.No & Oil & Surfactant & Co-surfactant & $\begin{array}{c}\text { Smix } \\
\text { Ratio }\end{array}$ \\
\hline 1. & Capmul MCM & Cremophor RH 40 & Transcutol P & 1:1 to 1:9 \\
2. & Capmul MCM & Cremophor RH 40 & Transcutol P & 2:1 to 9:1 \\
3. & Capmul MCM & Brij 35 & Transcutol P & $2: 1$ to 9:1 \\
4. & Triacetin & Cremophor RH 40 & Transcutol P & $1: 1$ to 1:9 \\
5. & Triacetin & Cremophor RH 40 & Transcutol P & $2: 1$ to 9:1 \\
6. & Triacetin & Brij 35 & Transcutol P & $1: 1$ to 1:9 \\
7. & Triacetin & Brij 35 & Transcutol P & $2: 1$ to 9:1 \\
8. & Caprylic Acid & Cremophor RH 40 & Transcutol P & $2: 1$ to 9:1 \\
\hline
\end{tabular}


(16.7); Span 20 (8.6). Saturation solubility of the drug in various oils, surfactants and co-surfactants were listed in Table 2.

\section{Construction of ternary phase diagrams}

Self-emulsifying region was determined by constructing Ternary Phase diagram of various mixture of oil, surfactant and cosurfactants, from this emulsifying region suitable concentration of components were selected for better formulation. ${ }^{29}$ From the phase diagrams, we observed that MCTs showed large nanoemulsion areas due to their high polarity and lower hydrophobicity. ${ }^{28}$ Different ratios of oils and surfactants trails are done which are listed in Table 1 and phase diagrams are presented in the form of Figures 1 to 2. The S-mix ratios of cremophor RH 40and brij 35 as a surfactant and transcutol Pas co-surfactant from 1:1 to 1:9 and 2:1 to 9:1 has shown very broad emulsifying region for triacetin oil. When capmul MCM as oil phase S-mix cremophor RH 40 and transcutol $\mathrm{P}$ shows a broad region from 2:1 to 9:1. In the case of caprylic acid as the oil phase, an S-mix cremophor RH 40 and transcutol P shows the nano region from 2:1 to 9:1. From the phase diagrams, 16 ratios of formulations were selected consisting of high concentration of oil which helps in dissolving more drug were shown in Table 3 and further subjected to characterization. ${ }^{8}$

\section{Percent transmittance}

Each undiluted formulation was diluted up to $5 \mathrm{ml}$ then the percent transmittance was checked at $254 \mathrm{~nm}$ by using a UVvisible spectrophotometer. The following are the results of percent transmittance formulations values in Table 3. By observing all values the formulations prepared by capmul MCM and triacetin as oil, cremophor RH 40as a surfactant and transcutol P as co-surfactant show greater percent transmittance values (above 95\% ) when compared with other formulations. From the values of percent transmittance formulations A1, A2, A3, A4, C1 and C2 formed clear solutions that indicate nanosize range particles. ${ }^{8}$ The formulations which can form clear solutions obtained from the percent transmittance values are carried to the next evaluation tests.

\section{Self-emulsification time}

Ability of the formulation to form an emulsion when getting contact with the aqueous phase will be determined by self-emulsification time which is a rate-limiting step for SNEDDS similar to the disintegration in case of tablets dosage forms. The values of self-emulsification time were presented in Table 4. Assessment of the emulsification time will also ensures no further precipitation in the dispersed o/w emulsion.
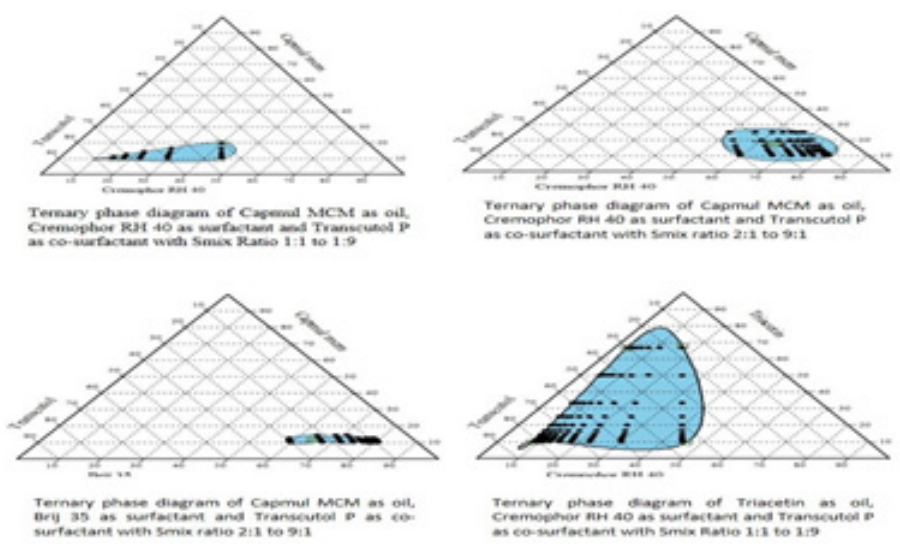

Figure 1: Ternary Phase diagram of various mixture of oil, surfactant and cosurfactants.
Dispersibility test, Phase separation and Precipitation, Visual assessment of emulsification ability and Particle size analysis

Visual observations for phase separation and precipitation, emulsification ability of SNEDDS formulations were reported in Table 4. All formulations were found to grading A dispersibility with no precipitation and no phase separation.

From the particle size analysis values shows that all formulations were present with in nano region and PDI values were also shows homogenicity in particle size.

The dispersibility shows all formulations Grade A means, all formulations forming nanoemulsion in less than 1 min which is clear and transparent, high spreadability. X- no phase separation, $\mathrm{XX}$ - no precipitation,

\section{Table 2: Solubility of drug in various excipients.}

\begin{tabular}{ccc}
\hline Category & Name of the excipient & Solubility $(\mathrm{mg} / \mathrm{mL})$ \\
\hline Oils & Capmul MCM & 20.95 \\
Triacetin & 12.14 \\
Caprylic acid & 13.12 \\
Apricot kernel oil & 8.75 \\
Kalonji oil & 4.35 \\
Chia seed oil & 9.54 \\
Coconut oil & 2.172 \\
Corn oil & 0.649 \\
Neem oil & 0.584 \\
Arachis oil & 0.455 \\
Olive oil & 1.425 \\
Cremophor RH 40 & 68.2 \\
Brij 35 & 21.7 \\
Tween 80 & 10.845 \\
Span 80 & 5.476 \\
& Triton X - 100 & 3.278 \\
Transcutol P & 45.6 \\
PEG 200 & 8.75 \\
Tween 20 & 5.75 \\
Span 20 & 1.378 \\
\hline
\end{tabular}
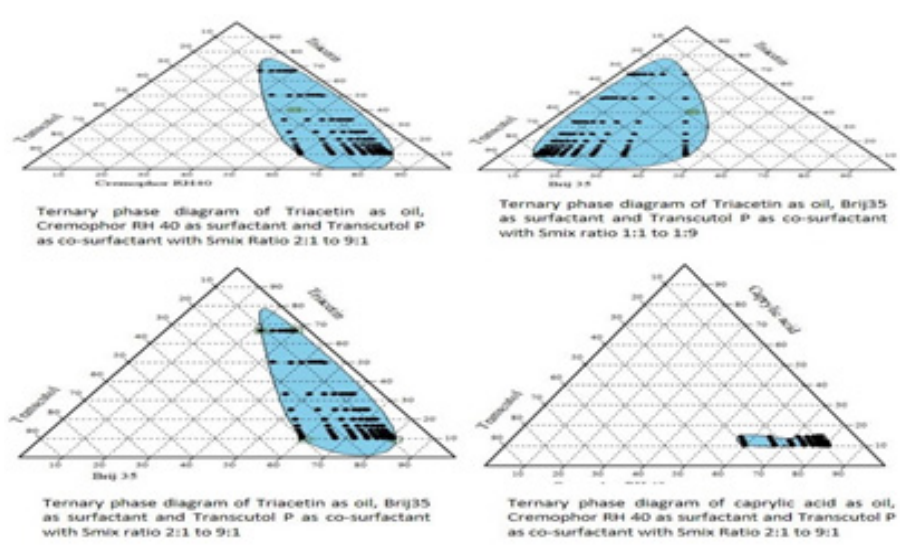

Figure 2: Ternary Phase diagram of various mixture of oil, surfactant and cosurfactants. 
Table 3: Selected ratios obtained from the ternary phase diagram and their Percentage transmittance values.

\begin{tabular}{|c|c|c|c|c|c|c|c|}
\hline \multirow[b]{2}{*}{ Formulation code } & \multicolumn{3}{|c|}{ Oil } & \multicolumn{2}{|c|}{ Surfactant } & \multirow{2}{*}{$\begin{array}{l}\text { Co-surfactant } \\
\text { (Transcutol P) }\end{array}$} & \multirow[t]{2}{*}{$\%$ Transmittance } \\
\hline & Capmul MCM & Triacetin & $\begin{array}{l}\text { Caprylic } \\
\text { acid }\end{array}$ & $\begin{array}{c}\text { Cremophor } \\
\text { RH } 40\end{array}$ & Brij 35 & & \\
\hline $\mathrm{A} 1$ & 20 & - & - & 42 & - & 38 & 98.9 \\
\hline $\mathrm{A} 2$ & 15 & - & - & 42 & - & 43 & 100.5 \\
\hline $\mathrm{A} 3$ & 25 & - & - & 65 & - & 10 & 100.2 \\
\hline A4 & 15 & - & - & 75 & - & 10 & 99.5 \\
\hline B1 & 09 & - & - & - & 79 & 12 & 86.9 \\
\hline B2 & 08 & - & - & - & 80 & 12 & 85.7 \\
\hline $\mathrm{C} 1$ & - & 30 & - & 06 & - & 64 & 99.8 \\
\hline $\mathrm{C} 2$ & - & 28 & - & 08 & - & 64 & 99.6 \\
\hline $\mathrm{C} 3$ & - & 28 & - & 66 & - & 06 & 89.3 \\
\hline $\mathrm{C} 4$ & - & 26 & - & 66 & - & 08 & 88.9 \\
\hline D1 & - & 22 & - & - & 14 & 64 & 88.0 \\
\hline D2 & - & 26 & - & - & 11 & 63 & 88.4 \\
\hline E1 & - & - & 26 & - & 65 & 04 & 89.9 \\
\hline E2 & - & - & 25 & - & 66 & 09 & 89.4 \\
\hline $\mathrm{F} 1$ & - & - & 11 & 75 & - & 14 & 88.7 \\
\hline F2 & - & - & 10 & 75 & - & 15 & 88.4 \\
\hline
\end{tabular}

Table 4: Evaluation results for Self emulsification time, Dispersibiltiy, Phase separation, Precipitation, Number of inversions, Particle Size and PDI values.

\begin{tabular}{|c|c|c|c|c|c|c|c|}
\hline Formulation & $\begin{array}{c}\text { Self-Emulsification } \\
\text { time (Sec) }\end{array}$ & Dispersion & Phase Seperation & Precipitation & No. of inversions & $\begin{array}{l}\text { Average Size of } \\
\text { Droplet(nm) }\end{array}$ & PDI \\
\hline $\mathrm{A} 1$ & 25.11 & Grade - A & $\mathrm{X}$ & $\mathrm{XX}$ & 4 & 239.5 & 0.749 \\
\hline A2 & 27.44 & Grade -A & $\mathrm{X}$ & $\mathrm{XX}$ & 4 & 289.3 & 0.632 \\
\hline A3 & 55.00 & Grade -A & $\mathrm{X}$ & $\mathrm{XX}$ & 8 & 157.8 & 0.366 \\
\hline A4 & 49.83 & Grade -A & $\mathrm{X}$ & $\mathrm{XX}$ & 6 & 158.5 & 0.399 \\
\hline $\mathrm{C} 1$ & 20.00 & Grade -A & $\mathrm{X}$ & $\mathrm{XX}$ & 3 & 165.9 & 0.332 \\
\hline $\mathrm{C} 2$ & 20.86 & Grade -A & $\mathrm{X}$ & $\mathrm{XX}$ & 4 & 185.8 & 0.486 \\
\hline
\end{tabular}

Table 5: In vitro Drug Release Profiles of screened formulations.

\begin{tabular}{|c|c|c|c|c|c|c|}
\hline \multirow{2}{*}{\multicolumn{2}{|c|}{$\begin{array}{l}\text { Time (min) } \\
\text { A1 }\end{array}$}} & \multicolumn{5}{|c|}{ Cumulative $\%$ drug release \pm standard deviation $(n=3)$} \\
\hline & & \multirow{2}{*}{$\frac{\mathrm{A} 2}{14.01 \pm 0.09}$} & \multirow{2}{*}{$\frac{\mathrm{A} 3}{40.48 \pm 1.62}$} & \multirow{2}{*}{$\frac{\mathrm{A} 4}{37.33 \pm 1.41}$} & \multirow{2}{*}{$\frac{\text { C1 }}{64.61 \pm 4.87}$} & \multirow{2}{*}{$\frac{C 2}{74.72 \pm 6.23}$} \\
\hline 5 & $1.55 \pm 0.08$ & & & & & \\
\hline 10 & $9.34 \pm 0.85$ & $67.73 \pm 3.81$ & $41.20 \pm 1.87$ & $53.71 \pm 1.61$ & $71.63 \pm 3.27$ & $78.63 \pm 6.17$ \\
\hline 15 & $9.34 \pm 0.76$ & $81.71 \pm 4.68$ & $66.17 \pm 2.64$ & $59.17 \pm 1.97$ & $74.75 \pm 3.21$ & $80.18 \pm 4.89$ \\
\hline 30 & $10.89 \pm 0.51$ & $84.81 \pm 4.65$ & $82.53 \pm 2.87$ & $70.07 \pm 1.86$ & $79.42 \pm 3.17$ & $80.18 \pm 6.78$ \\
\hline 45 & $31.14 \pm 1.19$ & $97.66 \pm 2.89$ & $89.54 \pm 1.79$ & $92.47 \pm 2.74$ & $91.09 \pm 4.68$ & $88.76 \pm 5.92$ \\
\hline 60 & $45.16 \pm 2.21$ & $97.67 \pm 2.89$ & $96.53 \pm 3.87$ & $97.32 \pm 2.67$ & $98.01 \pm 2.14$ & $93.44 \pm 5.73$ \\
\hline
\end{tabular}

\section{In vitro dissolution test}

The formulated SNEDDS were subjected to in vitro dissolution test to analyze the drug release from formulation. SNEDDS containing surfactant cremophor RH 40 and co-surfactant transcutol P; A1, A2, A3, A4, C1, C2 shows \% cumulative drug release within 60 min- 97.671\%, $82.537 \%, 96.539 \%, 97.320 \%, 98.010 \%, 93.440 \%$ respectively shown in Table 5 .

\section{DISCUSSION}

From the Solubility test results, we selected the oil phase as MCT's (capmul MCM, triacetin and caprylic acid) as they showed high solubility than LCT's this may be due to their shorter chain length which favors high solubilization and better fluidity. Cremophor RH 40 is selected as a surfactant and transcutol P as co-surfactant. 
With results obtained from ternary phase diagrams S-mix ratios of cremophor RH 40 and brij 35 as a surfactant and transcutol P as cosurfactant and triacetin as oil phase and capmul MCM as oil phase s-mix cremophor RH 40 and transcutol P are surfactant and co-surfactant increased concentration of surfactant we can observe that with increase in concentration of surfactant and co-surfactant an increase in the self-emulsifying region was observed. In the case of caprylic acid as the oil phase, an s-mix cremophor RH 40 and transcutol $\mathrm{P}$ shows the nano region from 2:1 to 9:1 indicating that higher amount of surfactant favoring nano emulsion region. From the phase diagrams formulations were selected which consisting of high concentration of oil which helps in dissolving more drug. ${ }^{8}$

By observing all values the formulations prepared by capmul MCM and triacetin as oil, cremophor RH 40 as a surfactant and transcutol P as co-surfactant show greater percent transmittance values (above 95\%) when compared with other formulations. From the values of percent transmittance formulations $\mathrm{A}, \mathrm{B}$ and $\mathrm{D}$ formed clear solutions that indicate nano-size range particles. ${ }^{8}$ The formulations which can form clear solutions obtained from the percent transmittance values are carried to the next evaluation tests.

Assessment of the emulsification time will also ensures no further precipitation in the dispersed o/w emulsion. From the results, we can observe that formulation having a low concentration of surfactant and high concentration of co-surfactant forms rapid nanoemulsion because the co-surfactant helps in a decrease in the interfacial tension to a negative value at that time rapidly form fine dispersions. ${ }^{8}$ SNEDDS containing high concentration of oil and surfactant was found to take more time for emulsification. The high concentration of surfactant may result in the formation of the gel upon contact with water resulting in slow dispersions and emulsification ${ }^{30,31}$

The formulations containing a high concentration of co-surfactant have shown lesser inversions $(<5)$ to form an emulsion. The nature of cosurfactant is decreasing in the interfacial tension to a negative value at that time rapidly form fine dispersions. The formulations with a high concentration of surfactant shown more inversions when compared with fewer concentration formulations $(<13)$ because the surfactant gets into a gel when getting contact with water, then it requires more shear rate to form an emulsion..$^{25}$ These results were correlated with self-emulsification time which shows that a high concentration of surfactant requires more time and little agitation to form an emulsion; a high concentration of cosurfactant requires less time.

Concentration of surfactant helps in reducing the size of the particle when compared to the co-surfactant concentration; the small-sized particles obtained due to closely packed surfactant film at oil in water interface, which helps in enhancing absorption through lymphatic (Figure 3). When compared with a pure drug (45\%), SNEDDS had shown increased drug release from the formulation (comparative dissolution profile illustrated in Figure 4), which was clear evidence for enhanced dissolution of candesartan cilexitil which may be attributed to the spontaneous formation of nanoemulsion in vitro with a decreased particle size that leads to the increased surface area leaving the drug candesartan as finely dispersed particles in dissolution media that can be attributed to good compositions of the three components used in the formulation from all the dissolution values the formulations A3, A4 has shown burst release with $37 \%$ and $41 \%$ of drug release respectively, when we look into the composition of these formulations we can observe the presence of higher surfactant concentrations. As the concentration of surfactant increases particle size decreases significantly $(p<0.05)$ $(n=3)$ which can be proven with low particle size $(130.83 \mathrm{~nm}$ and 158.51 $\mathrm{nm}$ respectively) and high percent transmittance (100.5\% and $99.5 \%$ respectively) values thereby increase in surface area and decreases

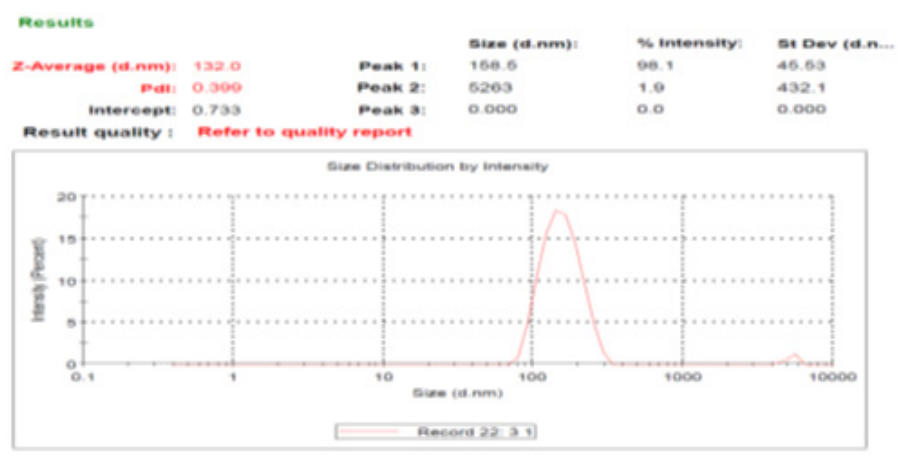

Figure 3: Particle size analysis of formulation A4.

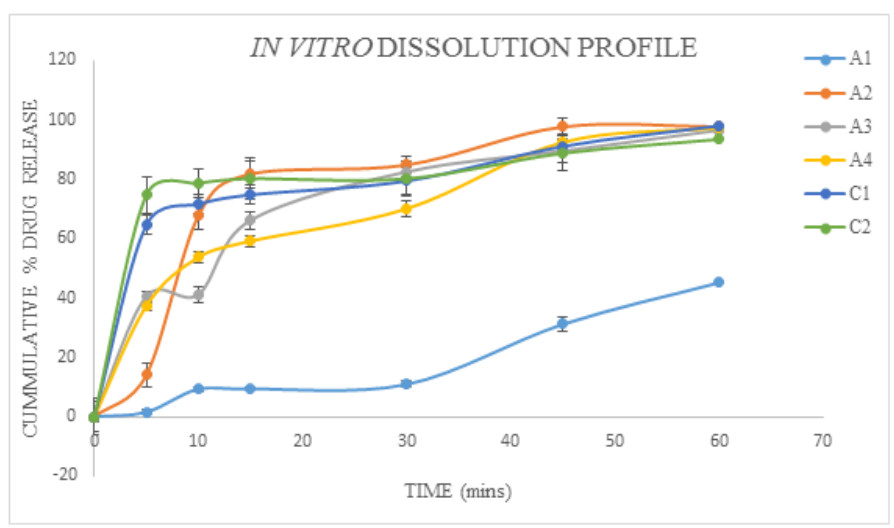

Figure 4: In vitro Drug Release Profile of screened SNEDDS formulations (drawn by taking average \pm standard deviation values of cumulative $\%$ drug dissolved in triplicate, $n=3$ ).

interfacial area helps in the formation of an emulsion by protecting and dissolving more amount of drug into the aqueous phase. ${ }^{8}$ In the case of formulation C1, C2 shows burst release $64 \%$ and $75 \%$ respectively; these formulations contain a high concentration of co-surfactant with particle size $165.9 \mathrm{~nm}$ and $185.8 \mathrm{~nm}$ respectively. Even though the particle size of $\mathrm{C} 1$ and $\mathrm{C} 2$ were higher when compared to A03 and A04, more burst release can be attributed to Co-surfactant decreasing in the interfacial tension to a negative value at that time rapidly form fine dispersion and helps in solubilization. ${ }^{8}$

\section{CONCLUSION}

SNEDDS are shown a drastic effect on the improvement of drug solubility and dissolution. In spite of the promising effects of SNEDDS such as tight junction opening, efflux pump inhibition and drug transport through the lymphatic system we mainly focused on the formulation of SNEDDS towards increasing bioavailability of candesartan cilexetil. Candesartan Cilexetil loaded SNEDDS was formulated successfully. Following the evaluation, the formulation consists of triacetin oil $30 \% \mathrm{w} / \mathrm{w}$, cremophore $\mathrm{RH} 406 \% \mathrm{w} / \mathrm{w}$ and transcutol P $64 \% \mathrm{w} / \mathrm{w}$ showed best emulsification characteristics like $99 \%$ percent transmittance, with increased dissolution profile (98\%) than pure drug (45\%) with nano range goblet size.

\section{ACKNOWLEDGEMENT}

Authors were thankful to authority of Acharya Nagarjuna University for providing facilities to carry out research work

\section{CONFLICT OF INTEREST}

The authors declare no conflict of interest. 


\section{ABBREVIATIONS}

SNEDDS: Self nano emulsifying drug delivery systems; PDI: Poly dispersibility index; CDN: Candesartan cilexetil; ARBs: Angiotensin Receptor Blockers; BCS: Biopharmaceutical Classification System.

\section{REFERENCES}

1. Jeevana JB, Sreelakshmi K. Design and evaluation of self-nanoemulsifying drug delivery system of flutamide. J Young Pharm. 2011;3(1):4-8

2. Parmar K, Patel J, Sheth N. Self nano-emulsifying drug delivery system for Embelin: Design, characterization and in vitro studies. Asian J Pharm Sci. 2015;10(5):396-404.

3. Dash RN, Mohammed H, Humaira T, Ramesh D. Design, optimization and evaluation of glipizide solid self-nanoemulsifying drug delivery for enhanced solubility and dissolution. Saudi Pharm J. 2015;23(5):528-40.

4. Date AA, Nagarsenker MS. Design and evaluation of self-nanoemulsifying drug delivery systems (SNEDDS) for cefpodoxime proxetil. Int J Pharm. 2007; 329(12):166-72.

5. Obitte NC, Ofokansi KC, Nzekwe IT, Esimone CO, Okoye IE. Selfnanoemulsifying drug delivery systems based on melon oil and its admixture with a homolipid from Bos indicus for the delivery of indomethacin. Trop J Pharm Res. 2011;10(3):299-307.

6. Wang L, Dong J, Chen J, Eastoe J, Li X. Design and optimization of a new selfnanoemulsifying drug delivery system. J Colloid Interface Sci. 2009;330(2):443-

7. Hong JY, Kim JK, Song YK, Park JS, Kim CK. A new self-emulsifying formulation of itraconazole with improved dissolution and oral absorption. J Controlled Release. 2006;110(2):332-8.

8. Narkhede RS, Gujar KN, Gambhire VM. Design and evaluation of self-nanoemulsifying drug delivery systems for nebivolol hydrochloride. Asian J Pharm Sci. 2014;8(3):200-9.

9. Gupta R, Gupta VP. Hypertension epidemiology in India: Lessons from Jaipur heart watch. Curr Sci. 2009;10:349-55.

10. Satturwar P, Eddine MN, Ravenelle F, Leroux JC. PH-responsive polymeric micelles of poly (ethylene glycol)-b-poly (alkyl (meth) acrylate-co-methacrylic acid): Influence of the copolymer composition on self-assembling properties and release of candesartan cilexetil. Eur J Pharm Biopharm. 2007;65(3):379-87.

11. Sravya M, Deveswaran R, Bharath S, Basavaraj BV, Madhavan V. Development of orodispersible tablets of candesartan cilexetil- $\beta$-cyclodextrin complex. J Pharmaceutics. 2013.

12. Verma P, Singh B, Chaudhary H. Solid Dispersion of Oral Candesartan Cilexetil Tablets For Hypertension: Development and Characterisation. Int J Pharm Sci Res. 2017;8(11):4795-802

13. Jain S, Reddy VA, Arora S, Patel K. Development of surface stabilized candesartan cilexetil nanocrystals with enhanced dissolution rate, permeation rate across CaCo-2 and oral bioavailability. Drug Deliv Transl Re. 2016;6(5):498510.

14. Senapati PC, Sahoo SK, Sahu AN. Mixed surfactant based (SNEDDS) self-nanoemulsifying drug delivery system presenting efavirenz for enhancement of oral bioavailability. Biomed Pharmacother. 2016;80:42-51.
15. Singh B, Khurana L, Bandyopadhyay S, Kapil R, Katare OO. Development of optimized self-nano-emulsifying drug delivery systems (SNEDDS) of carvedilol with enhanced bioavailability potential. Drug Deliv. 2011;18(8):599-612.

16. Khade S, Pore Y. Formulation and Evaluation Of Neusilin® Us2 Adsorbed Amorphous Solid Self-Microemulsifying Delivery System of Atorvastatin Calcium. Asian J Pharm Clin Res. 2016:9:93-100.

17. Patel J, Patel A, Raval M, Sheth N. Formulation and development of a self-nanoemulsifying drug delivery system of irbesartan. J Pharm Adv Res.2011;2(1):9-16.

18. Raval C, Joshi N, Patel J, Upadhyay UM. Enhanced oral bioavailability of olmesartan by using novel solid self-emulsifying drug delivery system. Int J Adv Pharm. 2012;2(2):82-92

19. Bhagwat DA, Souza JI. Formulation and evaluation of solid self-micro emulsifying drug delivery system using aerosil 200 as solid carrier. Int Cur Pharm J. 2012;1(12):414-9.

20. Forgiarini A, Esquena J, Gonzalez C, Solans C. Formation of nano-emulsions by low-energy emulsification methods at constant temperature. Langmuir $2001 ; 17(7): 2076-83$

21. Solans C, Solé I. Nano-emulsions: formation by low-energy methods. Current Opinion in Colloid and Interface Science. 2012:17(5):246-54.

22. Bali V, Ali M, Ali J. Study of surfactant combinations and development of a novel nanoemulsion for minimising variations in bioavailability of ezetimibe. Colloids Surf B. 2010;76(2):410-20.

23. Zhang P, LiuY, Feng N, Xu J. Preparation and evaluation of self-microemulsifying drug delivery system of oridonin. Int J Pharm. 2008; 355(1-2):269-76.

24. Khan AW, Kotta S, Ansari SH, Sharma RK, Ali J. Self-nanoemulsifying drug delivery system (SNEDDS) of the poorly water-soluble grapefruit flavonoid Naringenin: Design, characterization, in vitro and in vivo evaluation. Drug Deliv. 2015;22(4):552-61

25. Ahmed OA, Badr-Eldin SM, Tawfik MK, Ahmed TA, Khalid M, Badr JM. Design and optimization of self-nano-emulsifying delivery system to enhance quercetin hepato protective activity in paracetamol-induced hepatotoxicity. J Pharm Sci. 2014;103(2):602-12.

26. Shafiq S, Shakeel F, Talegaonkar S, Ahmad FJ, Khar RK, Ali M. Development and bioavailability assessment of ramipril nanoemulsion formulation. Eur J Pharm Biopharm. 2007;66(2):227-43.

27. Elnaggar YS, El-Massik MA, Abdallah OY. Self-nanoemulsifying drug delivery systems of tamoxifen citrate: Design and optimization. Int J Pharm. 2009;380(12):133-41.

28. Bandyopadhyay S, Katare OP, Singh B. Optimized self nano-emulsifying systems of ezetimibe with enhanced bioavailability potential using long chain and medium chain triglycerides. Colloids Surf B. 2012;100:50-61.

29. Balakrishnan P, Lee BJ, Oh DH, Kim JO, Hong MJ, Jee JP, et al. Enhanced oral bioavailability of dexibuprofen by a novel solid self-emulsifying drug delivery system (SEDDS). Eur J Pharm Biopharm. 2009;72(3):539-45.

30. Abd-Elhakeem E, Teaima MH, Abdelbary GA, EIMahrouk GM. Bioavailability enhanced clopidogrel-loaded solid SNEDDS: Development and in vitro/in vivo characterization. J Drug Deliv SciTec. 2019;49:603-14.

31. Jia B, Zhang Z, Chen MH, Zhang WP. Effect of liquid oils on the properties of multiple emulsions containing liquid crystals. J Dispersion Sci Technol. 2017;38(6):876-82

Article History: Submission Date : 15-04-2020; Revised Date : 05-09-2020; Acceptance Date : 11-10-2020.

Cite this article: Raghuveer P, Rani AP. Self Nano-emulsifying Drug Delivery System to Enhance Solubility and Dissolution of Candesartan Cilexetil. Int. J. Pharm. Investigation, 2020;10(4):506-11. 